\title{
Reconstruction of soft tissue defect after maxillectomy of ameloblastic carcinoma with submental island flap: a case report and literature review
}

\author{
Zhenqi Xu ${ }^{1}$, Jianwei Shang ${ }^{2}$, Nan Yang ${ }^{3}$, Li Long ${ }^{1}$, Ping Zhang ${ }^{1}$ \\ ${ }^{1}$ Department of Oral and Maxillofacial Surgery, Tianjin Key Laboratory of Oral and Maxillofacial Function Reconstruction, Tianjin Stomatological \\ Hospital, Hospital of Stomatology, Nankai University, Tianjin, China; ${ }^{2}$ Department of Oral Pathology, Tianjin Stomatological Hospital, Hospital \\ of Stomatology, Nankai University, Tianjin, China; ${ }^{3}$ Department of Nursing, Tianjin Stomatological Hospital, Hospital of Stomatology, Nankai \\ University, Tianjin, China \\ Correspondence to: Zhenqi Xu. Tianjin Stomatological Hospital, No. 75 Dagu North Road, Heping District, Tianjin 300041 , China. \\ Email: hugoxuarticles@hotmail.com.
}

\begin{abstract}
Ameloblastic carcinoma (AC) is an extremely rare malignant odontogenic tumor. The mean age of occurrence for all $141 \mathrm{AC}$ cases analyzed in our systematic review study was $43.59 \pm 19.51$ years. Males were more affected than females, and the mandible was predominantly affected compared with the maxilla. The main clinical manifestation was a painful or painless swelling with ulceration and radiographic features usually displayed as mixed cystic or solid changes. Surgical resection was the first recommended method of management. Fourteen cases had cervical lymph node spread, 19 had distant metastasis (most commonly in the lung), and 33 had recurrence. We present a rare case of AC involving the maxillary region. Locally extensive surgical resection was carried out. Ablative defects after maxillectomy resulted in the communication of oral cavity and nasal cavity/maxillary antrum and would bring about difficulties in mastication, deglutition, and speech. A submental island flap was applied to close the oronasal and oroantral fistula. The flap and the wounds healed well, with excellent outcomes in terms of appearance, the function of speech, and swallowing on follow up. The submental island flap provides a relatively thin, easy-to-harvest, and well-vascularized tissue, which makes it a reliable option in soft tissue reconstruction of the oral and maxillofacial region.
\end{abstract}

Keywords: Ameloblastic carcinoma (AC); submental island flap; tissue defect; maxillectomy; case report

Submitted Sep 10, 2021. Accepted for publication Nov 12, 2021.

doi: 10.21037/atm-21-5196

View this article at: https://dx.doi.org/10.21037/atm-21-5196

\section{Introduction}

Ameloblastic carcinoma (AC) is a rare malignant odontogenic tumor with characteristic histological features and clinical aggressive behavior that are distinct from a conventional ameloblastoma. The mandible is the most reported site, followed by the mandible, the ratio of occurrence of AC in mandible: maxilla was about 2-3:1 (1). We present a case of AC involving the maxillary region and systematically evaluated the literature to collect more information about AC.

The etiology of AC ameloblastic carcinoma has not been clearly elucidated till now. Most cases arise spontaneously without a previous history of cancer, while, few cases may develop from the malignant transformation of ameloblastoma (1).

Locally extensive surgical resection is the first choice of management in AC. Ablative defects after maxillectomy

\footnotetext{
$\wedge$ ORCID: 0000-0001-5254-6724.
} 

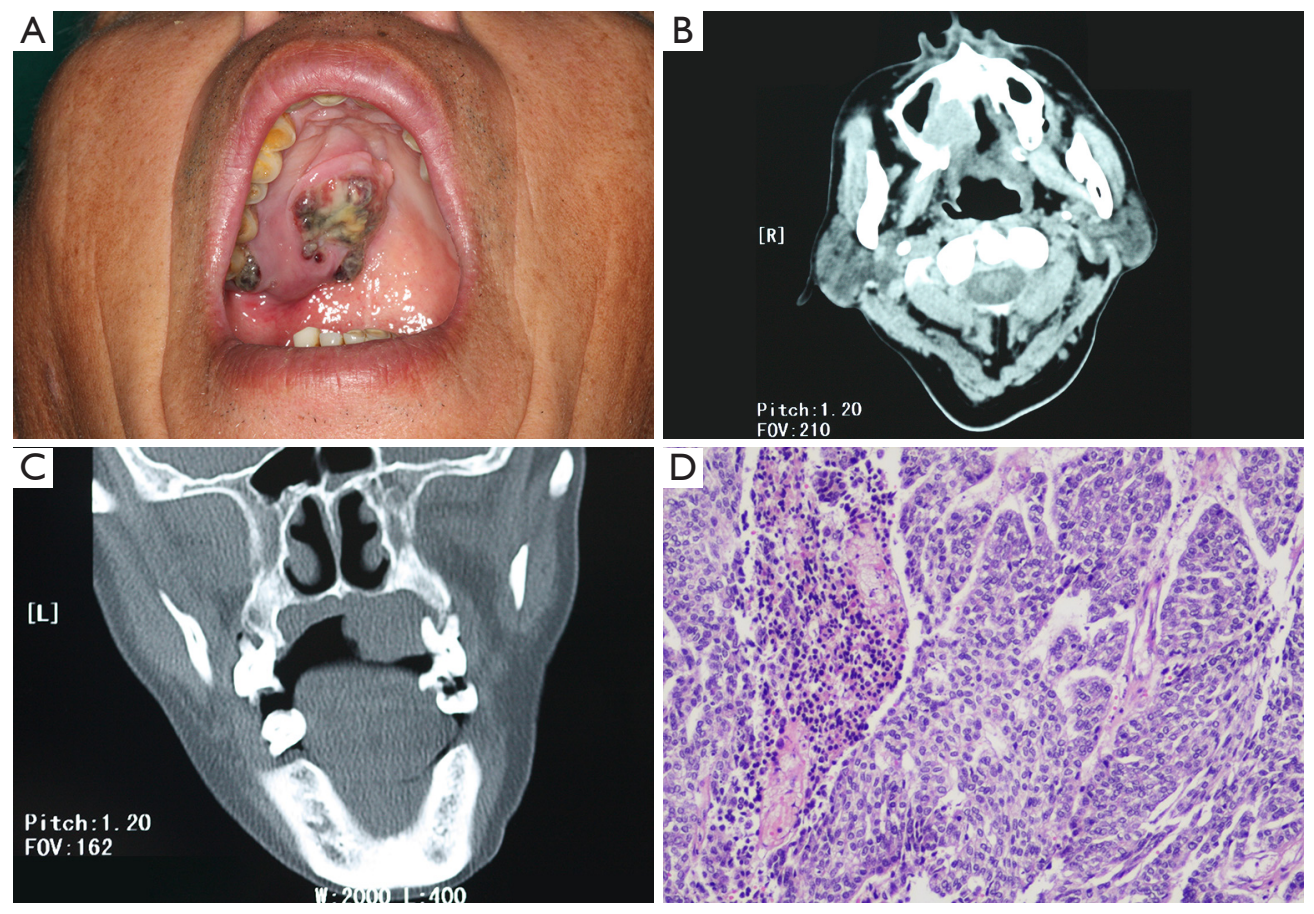

Figure 1 Preoperative clinical examination and biopsy. (A) Preoperative intraoral view; (B) preoperative computed tomography (CT) scan in horizontal view; (C) preoperative CT scan in coronal view; (D) histopathological presentation (HE staining, $\times 100$ ).

usually involve the bone, teeth, muscle, cartilage, and mucosa, which often result in the communication of oral cavity and nasal cavity or maxillary antrum, and cause difficulties in mastication, deglutition, and speech. Therefore, an appropriate substitute for tissue loss is necessary to restore function, aesthetics, and quality of life (QoL). Although prosthetic obturation offers patients a simple method of functional oral rehabilitation, daily maintenance and hygiene may represent a problem, particularly in the elderly or handicapped. In the previous decades, submental island flap has been widely used as a reliable option in head-and-neck reconstruction and confirmed as an effective technique for reconstruction of extensive palatal defects after maxillectomy (2).

A submental island flap was applied in our study to repair the oronasal and oroantral fistula after surgery to restore the patient's post-operational speech and eating. We present the following article in accordance with the CARE reporting checklist (available at https://dx.doi. org/10.21037/atm-21-5196).

\section{Case presentation}

A 60-year-old male was admitted to the Department of
Oral and Maxillofacial Surgery of Tianjin Stomatological Hospital with a main complaint of an ulcerated and painless swelling in his upper right back tooth region for 2 years. The mass had suddenly started increasing in size over the past 6 months, which resulted in some difficulty in mastication and swallowing. Past medical history revealed that the patient was otherwise healthy and had no systemic diseases.

Extraoral examination showed no facial asymmetry or paresthesia. On intraoral examination, a single, ovoidshaped, and ulcerated mass was seen measuring about $3 \mathrm{~cm} \times 2.5 \mathrm{~cm}$ in the right posterolateral region of the hard palate. The swelling extended anteriorly from region 14 to 17 posteriorly. Medially, it extended to the midline of the palate about $5 \mathrm{~mm}$, and laterally to the palatal free gingiva of the molar region. The overlying mucosa appeared ulcerated (Figure 1A). On palpation, the swelling was firm, non-tender, not cystic, immovable, and poorly defined margins. There was an associated burning sensation and fetid odor, but no tooth mobility. There was no palpable lymphadenopathy or mass in the neck.

Computed tomography (CT) scan showed a mass involving the right posterior maxilla, infiltrating the ground floor of the right maxillary sinus and extending over the 

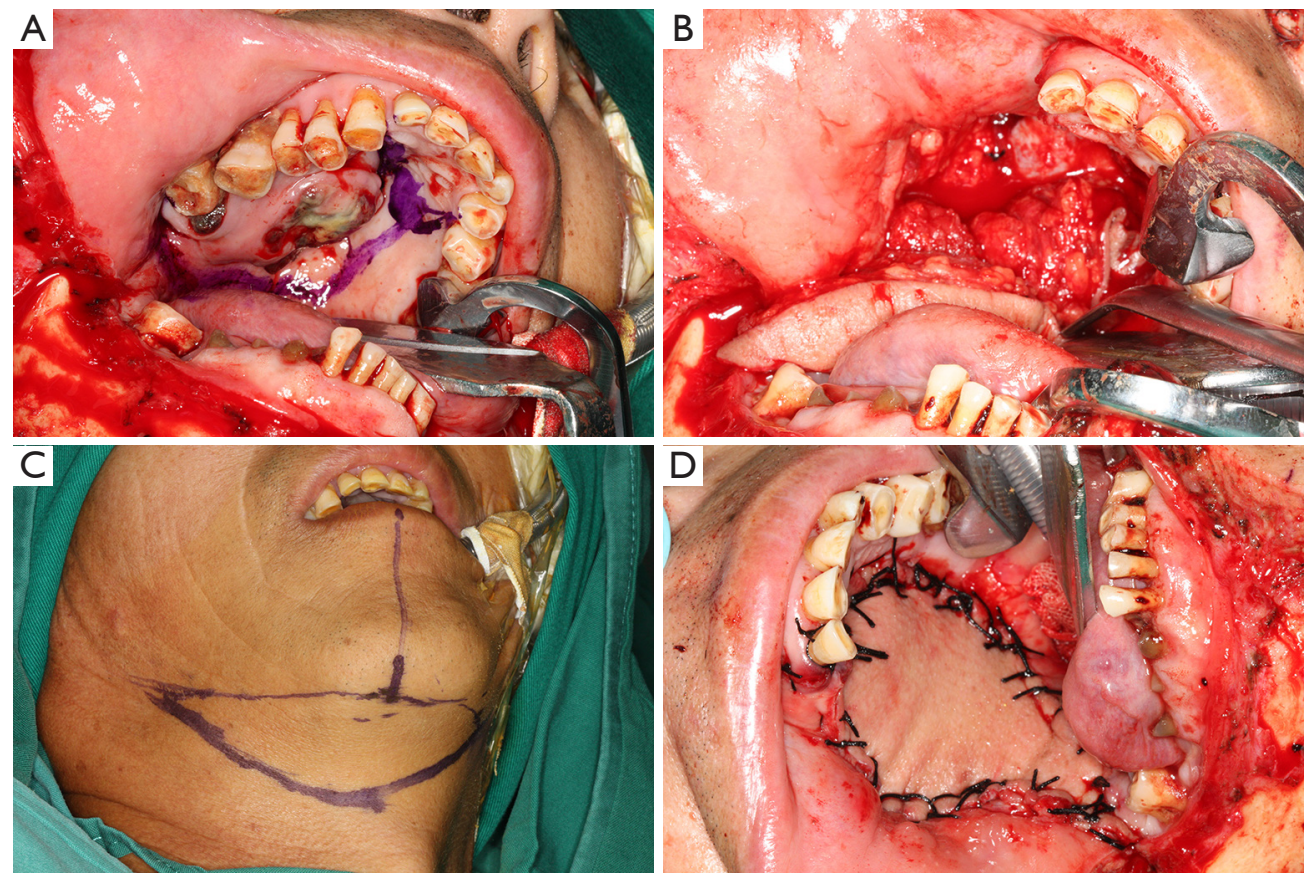

Figure 2 Excision of the tumor and reconstruction of the defect. (A) Designated incisive line of the tumor; (B) tissue defect after maxillectomy; (C) fabrication of the submental island flap; (D) closure of oro-nasal and oroantral communication.

midline of the palate (Figure $1 B, 1 C$ ). Chest $\mathrm{X}$-ray and CT of the neck did not reveal metastatic disease.

The initial diagnosis was pleomorphic adenoma or mucoepidermoid carcinoma. A biopsy specimen was obtained under local anesthesia. On histopathological examination, ameloblast-like odontogenic epithelium arranged in the form of island and cord, the cells were highly pleomorphic with increased cellular atypia and mitotic activity showing a feature of invasive growth (Figure 1D). According to the microscopic presentations, a histopathological diagnosis of AC was made.

The diagnostic criteria of an ameloblastic carcinoma that distinguishes it from ameloblastoma are based largely on cytologic atypia and increased mitotic figures. Microscopically, our case retained some of the typical histologic features of ameloblastoma, while malignant features, such as atypia, local necrosis, and mitosis, were observed. Thus, ameloblastic carcinoma was diagnosed.

After preparation of routine work, extensive surgical excision was performed under general anesthesia for composite block resection with subtotal maxillectomy with a safe margin of $2 \mathrm{~cm}$ (Figure $2 A, 2 B$ ). Immediate reconstruction was done with a submental island flap, as the patient did not consent to further bone reconstruction
(Figure 2C,2D). Neck lymph node dissection in region I and II was done during the fabrication of the flap. Preventive tracheostomy was performed to avoid postoperative asphyxia. Histopathological examination of surgical specimens confirmed the diagnosis of AC, and no lymph node metastasis was observed. The study was approved by the Tianjin Stomatological Hospital Ethics Committee (No. TJSH-2020-120). Written informed consent was obtained from the patient for publication of this case report and accompanying images. A copy of the written consent is available for review by the editorial office of this journal. The study was conducted in accordance with the Declaration of Helsinki (as revised in 2013).

\section{Literature review of $\mathbf{A C}$}

Eligible literatures in English were searched in PubMed from January 2015 until June 2021based on the following $\mathrm{MeSH}$ term- "ameloblastic carcinoma". The inclusion criteria were case reports, case series, and retrospective studies. The exclusion criteria were conference abstracts, reviews, and articles with unavailable full text. Eighteen full-length studies were extracted for inclusion, and clinical and radiographic features of AC were recorded (1,3-22). 


\section{Page 4 of 8}

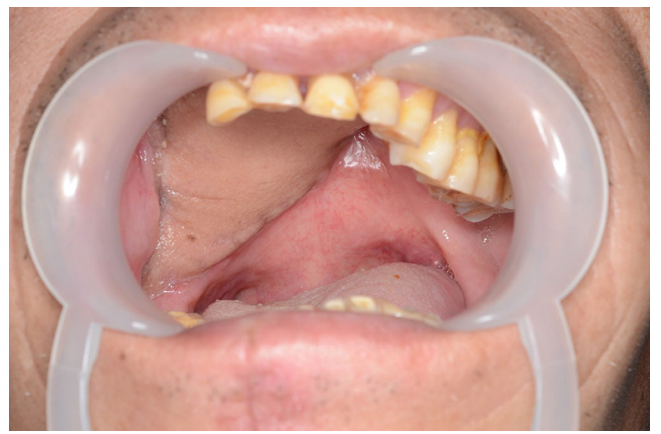

Figure 3 Postoperative intraoral view on 3-month follow up.

The postoperative period was uneventful and the patient was discharged from hospital after 2 weeks. The patient was followed up 3 months after the operation. The flap and the wounds healed well, and there was no bucking when eating or drinking and no difficulty in swallowing (Figure 3). Clearance in pronunciation and speech function was acceptable. There was no sign of recurrence at the 1.5-year follow up.

\section{Characteristics of $A C$}

In the systematic reviews, the age of the 141 cases ranged from 5 to 91 years, with a mean age of $43.59 \pm 19.51$ years. Males were more frequently affected than females (2.07:1), and the mandible was predominantly involved than the maxilla (6.83:1). Clinically, the main complaint was ulcerated swelling with or without pain. Radiographic presentation was similar to ameloblastoma as a unicystic and/or multilocular radiolucency. Surgical resection was the most commonly recommended method of management. Some cases received additional postoperative radiotherapy and/or chemotherapy, and some underwent isolated radiotherapy and/or chemotherapy. Fourteen cases had regional lymph node spread, 19 had distant metastasis (e.g., lung, brain, bone), and 33 cases had recurrence during the follow-up period.

\section{Discussion}

Ameloblastoma is the most frequently reported odontogenic tumor, which is generally recognized as a benign lesion, although biologically it behaves locally invasive and demonstrates considerable tendency to recur (23). However, rare cases can metastasize to distant sites, such as the lung, and can even exhibit malignant features. The question about the malignant nature of ameloblastoma has been a subject of considerable discussion and controversy for many years.

Different terms have been used to designate malignancies associated ameloblastoma, such as malignant ameloblastoma (MA), metastatic ameloblastoma (MM), AC, and primary intra-alveolar epidermoid carcinoma. Of these, MA, MM, and $\mathrm{AC}$ have been frequently mentioned in previous articles (24). Even in the World Health Organization (WHO) classification of head and neck tumors, the classification of malignant odontogenic tumors is modifying according to the updating knowledge about the diseases. In the new edition of WHO, MA and MM are interchangeable, but the difference between MA and AC is again addressed. MA has been moved from the section of malignant odontogenic tumors and has been recognized as a type of benign conventional ameloblastoma, which is defined as an ameloblastoma that can metastasize to distant sites; however, both the primary lesion and metastasis must have histological features of well-differentiated benign cells. AC is a type of malignant odontogenic tumor with malignant histological features independent of metastasis (25).

AC is an extremely rare malignant tumor of odontogenic epithelium origin that represents a challenge in its diagnosis, treatment, and prognosis because of the information regarding its clinical features is limited. In 1982, Elzay found that ameloblastoma may exhibit malignant features other than metastasis, and the term "ameloblastic carcinoma" was coined (26). In 1984, AC was differentiated from MA (27). In 2005, AC was first referred to by WHO and divided into three types: primary, secondary intraosseous, and secondary peripheral. However, there was little need to divide such a rare tumor, therefore in the new edition of the WHO 2017 classification, a single entity of AC was recommended (25).

The exact demographic data of AC is unclear, because most articles are case reports. According to the reported articles, most ACs occur in the posterior mandible, but about one-third of cases were found in the maxilla. Patients vary in age from 4 to 90 years old with an average age of 44 years old. The male-to-female ratio was 1.75:1. Common clinical sign of AC is rapid swelling. On the basis of our systematic research, AC is more common in males compared with females, and the preferred site of distribution is the mandible, particularly in the posterior mandible. The age of occurrence showed a large range, with an average age of $43.59 \pm 19.51$ years. The common clinical signs and symptoms are usually a cystic lesion with benign clinical features or a large tissue mass with 
Table 1 Demographics and clinical characteristics of patients with AC

\begin{tabular}{|c|c|c|c|c|c|c|c|c|c|c|c|}
\hline Study & Age (years) & \multicolumn{2}{|c|}{ Sex } & \multicolumn{2}{|c|}{ Site } & \multicolumn{2}{|c|}{ Presentation } & \multicolumn{3}{|c|}{ Metastasis } & -Recurrence \\
\hline Gunaratne et al. & 66 & 1 & & & 1 & Pain, swelling & $\begin{array}{l}\text { Well-defined, multilocular, } \\
\text { radiolucency }\end{array}$ & & & & 1 \\
\hline Fomete et al. & $43.50 \pm 16.26$ & 2 & & 2 & & Swelling, ulceration & Multilocular & & & & 1 \\
\hline Fonseca et al. & 27 & & 1 & & 1 & $\begin{array}{l}\text { Asymptomatic } \\
\text { swelling }\end{array}$ & $\begin{array}{l}\text { Multilocular radiolucent } \\
\text { image }\end{array}$ & & & & 1 \\
\hline Kodati et al. & $24.67 \pm 8.50$ & 2 & 1 & & 3 & Swelling & Unicystic and/or multilocular & & & & \\
\hline Moro et al. & 63 & & 1 & 1 & & Pain, swelling & Bone erosion & 1 & 1 & & 1 \\
\hline Pandey et al. & $43.48 \pm 21.10$ & 59 & 27 & & 86 & $\begin{array}{l}\text { Paresthesia, pain, } \\
\text { swelling }\end{array}$ & Similar to ameloblastoma & 10 & 8 & 7 & 21 \\
\hline Mahmoud et al. & $32.25 \pm 17.93$ & 1 & 3 & 1 & 3 & $\begin{array}{l}\text { Paresthesia, pain, } \\
\text { swelling }\end{array}$ & Multilocular radiolucency & & & & \\
\hline Soyele et al. & $36.85 \pm 15.51$ & 8 & 5 & 3 & 10 & $\begin{array}{l}\text { Pain, swelling, } \\
\text { ulceration }\end{array}$ & $\begin{array}{l}\text { Well- or poorly defined } \\
\text { multilocular radiolucency }\end{array}$ & & & & 2 \\
\hline Fahradyan et al. & 15 & 1 & & 1 & & Swelling & Unicystic & & & & \\
\hline Yamagata et al. & 70 & & 1 & 1 & & Swelling & $\begin{array}{l}\text { Mass with high signal } \\
\text { intensity }\end{array}$ & & & & \\
\hline Kosanwat et al. & 46 & & 1 & 1 & & Swelling & $\begin{array}{l}\text { Homogeneous radiopaque } \\
\text { mass }\end{array}$ & & & & 1 \\
\hline Deng et al. & $46.72 \pm 14.20$ & 14 & 4 & 4 & 14 & $\begin{array}{l}\text { Pain, swelling, } \\
\text { ulceration }\end{array}$ & $\begin{array}{l}\text { Mixed cystic and solid } \\
\text { changes }\end{array}$ & 2 & 1 & & 5 \\
\hline Cho et al. & 45 & 1 & & & 1 & Swelling & Bone resorption & & & & \\
\hline Shrikaar et al. & 52 & 1 & & 1 & & Swelling & $\begin{array}{l}\text { Poorly defined bone } \\
\text { resorption }\end{array}$ & & & & \\
\hline Salehani et al. & 61 & & 1 & & 1 & Swelling & Bone resorption & 1 & & 1 & \\
\hline
\end{tabular}

AC, ameloblastic carcinoma; F, female; LN, lymph node; $M$, male; $M n$, mandible; $M x$, maxillary.

ulceration, significant bone resorption, and tooth mobility. Presentation of radiographic examination is similar to that of ameloblastoma, which generally shows a unicystic or multilocular radiolucency or well-defined mass; tooth root resorption could be seen in some cases. Regional lymph node involvement and metastasis to distant sites 
(most frequently, the lung) had been reported; however, recurrence was more commonly observed in our study, which indicates that the typical characteristic biology of AC may be locally invasive growth other than cervical lymph node or hematogenous metastasis (Table 1).

A more radical surgical approach is recommended as the first choice in AC treatment compared with ameloblastoma. Regional lymph node involvement has been affirmed in some cases, but the management of neck dissection is controversial. Some researchers have noted that contiguous neck dissection should be considered both prophylactic and therapeutic, but more researchers accept that neck dissection should only be performed in the presence of clinically positive lymph nodes, especially when in the maxilla $(28,29)$. Patients may gain little benefit from radiotherapy and chemotherapy; however, it is said that adjuvant postoperative radiotherapy may improve the likelihood of local control, especially if margins are close or microscopically positive. Palliative treatment may be offered to those who refuse operation or cannot suffer from a surgical intervention because of anatomical restriction (15-17).

The patient in our article was 60 -year-old man. His main clinical presentation was an augmenting firm mass with ulceration involving the plate. After preparation, an extensive surgical approach was taken. Although there is no indication of lymph node metastasis in clinical examinations and CT scans, region I and II dissection was done simultaneously during the fabrication of the submental flap. The final pathological examination showed no lymph node metastasis and no adjuvant therapy was added after operation. According to our case, a more widely surgical resection than ameloblastoma should be the first modality of AC management, and prophylactic neck dissection is not advised.

Functionally, the maxilla separates the oral cavity and the nasal airway, and supports the globe of the eye and superior arch teeth. Aesthetically, it supports the facial soft tissues and nasal base. Ablative defects of the maxilla commonly lead to facial disfigurement, loss of vision, compromised speech, difficulty swallowing, and diminished overall QoL. Reconstruction of maxillary defects after oncological resection can be approached in several ways, depending on the site and size of the defect. The main objectives are to restore the intra-oral defect, separate the oral cavity and nose, provide support to the nasal base and to the soft tissues of the cheek and, in cases with skin invasion, replace the external coverage (30). In our study, the type of defect after resection is like class $I \mathrm{~b}$, the ground floor of sinus and nose base had been excised, and communication of the mouth-nose and mouth-antrum occurred, resulting in hypernasal speech and fluid leakage and causing difficulties in mastication, deglutition, and speech. The patient refused bone reconstruction, therefore a submental island flap was applied to close the oro-nasal and oro-antral fistula.

Submental artery island flap was first described by Martin et al. in 1990 (31). The flap has an excellent skin color match and wide arc of rotation, and can extend to the whole homolateral face and oral cavity. Over the past two decades, it has become a reliable choice, and even an alternate to free flap, in the reconstruction of oral cavity defects after infection, trauma, or tumor extirpation. It provides a relatively thin, easy-to-harvest, and well-vascularized tissue which eliminates the need for a second-stage operation of flap division or tedious microsurgical techniques of vascularized free flap, such as forearm flap and anterolateral thigh flap (32).

While reconstructing the oral cavity with submental flap, compromise on neck nodal clearance has always stayed as a major concern (33). However, AC behaves a lower incidence of lymph node metastasis, especially when it involves the maxilla, supporting submental artery island flap as a reliable option in soft tissue reconstruction. On 3-month follow up, the flap and the wounds healed well, and the patient achieved excellent outcomes in terms of appearance, speech, and swallowing. To date, there has been no recurrence.

\section{Conclusions}

$\mathrm{AC}$ is an extremely rare, aggressive, malignant epithelial odontogenic tumor. There is currently a lack of information on its pathogenesis, demographic features, clinical behavior, treatment, and prognosis. More clinical series and systematic studies would help to uncover its pathogenesis and establish the best therapeutic modality. Surgical resection with follow up is essential for the successful management of AC. A substitute for tissue loss after resection of AC is necessary to restore function, aesthetics, and QoL. Submental island flap provides a relatively thin, easy-to-harvest, and well-vascularized tissue, which makes it a reliable option in soft tissue reconstruction of the oral and maxillofacial region.

\section{Acknowledgments}

Funding: None. 


\section{Footnote}

Reporting Checklist: The authors have completed the CARE reporting checklist. Available at https://dx.doi. org/10.21037/atm-21-5196

Conflicts of Interest: All authors have completed the ICMJE uniform disclosure form (available at https://dx.doi. org/10.21037/atm-21-5196). The authors have no conflicts of interest to declare.

Ethical Statement: The authors are accountable for all aspects of the work in ensuring that questions related to the accuracy or integrity of any part of the work are appropriately investigated and resolved. The study was conducted in accordance with the Declaration of Helsinki (as revised in 2013). The study was approved by the Tianjin Stomatological Hospital Ethics Committee (No. TJSH-2020-120). Written informed consent was obtained from the patient for publication of this case report and accompanying images. A copy of the written consent is available for review by the editorial office of this journal.

Open Access Statement: This is an Open Access article distributed in accordance with the Creative Commons Attribution-NonCommercial-NoDerivs 4.0 International License (CC BY-NC-ND 4.0), which permits the noncommercial replication and distribution of the article with the strict proviso that no changes or edits are made and the original work is properly cited (including links to both the formal publication through the relevant DOI and the license). See: https://creativecommons.org/licenses/by-nc-nd/4.0/.

\section{References}

1. Deng L, Wang R, Yang M, et al. Ameloblastic carcinoma: Clinicopathological analysis of 18 cases and a systematic review. Head Neck 2019;41:4191-8.

2. Futran ND. Primary reconstruction of the maxilla following maxillectomy with or without sacrifice of the orbit. J Oral Maxillofac Surg 2005;63:1765-9.

3. Gunaratne DA, Coleman HG, Lim L, et al. Ameloblastic Carcinoma. Am J Case Rep 2015;16:415-9.

4. Fomete B, Adebayo ET, Ayuba GI, et al. Ameloblastic carcinoma of the maxilla: a report of two cases and a review of the literature. J Korean Assoc Oral Maxillofac Surg 2016;42:43-6.

5. Matsushita Y, Fujita S, Yanamoto S, et al. Spindle cell variant of ameloblastic carcinoma: a case report and literature review. Oral Surg Oral Med Oral Pathol Oral Radiol 2016;121:e54-61.

6. Fonseca FP, de Almeida OP, Vargas PA, et al. Ameloblastic carcinoma (secondary type) with extensive squamous differentiation areas and dedifferentiated regions. Oral Surg Oral Med Oral Pathol Oral Radiol 2016;121:e154-61.

7. Kodati S, Majumdar S, Uppala D, et al. Ameloblastic Carcinoma: A Report of Three Cases. J Clin Diagn Res 2016;10:ZD23-5.

8. Moro A, Foresta E, Gasparini G, et al. Ameloblastic carcinoma of the maxilla: A case report and an updated review of the literature. Oncol Lett 2016;12:4339-50.

9. Kiresur MA, Kunche A, Ananthaneni A, et al. A Rare Case Report of Spindle Cell Ameloblastic Carcinoma Involving the Mandible. J Clin Diagn Res 2017;11:ZD25-7.

10. Gawande PD, Khande K, Agrawal G, et al. Ameloblastic Carcinoma: A Rare Malignant Tumour in Maxillofacial Region. J Maxillofac Oral Surg 2017;16:377-81.

11. Pandey S, Bhutia O, Roychoudhury A, et al. Literature review of 86 cases of mandibular ameloblastic carcinoma. Natl J Maxillofac Surg 2018;9:2-7.

12. Mahmoud SAM, Amer HW, Mohamed SI. Primary ameloblastic carcinoma: literature review with case series. Pol J Pathol 2018;69:243-53.

13. Soyele OO, Adebiyi KE, Adesina OM, et al. Ameloblastic carcinoma: a clinicopathologic analysis of cases seen in a Nigerian Teaching Hospital and review of literature. Pan Afr Med J 2018;31:208.

14. Fahradyan A, Odono L, Hammoudeh JA, et al. Ameloblastic Carcinoma In Situ: Review of Literature and a Case Presentation in a Pediatric Patient. Cleft Palate Craniofac J 2019;56:94-100.

15. Yamagata K, Ishikawa H, Saito T, et al. Proton Beam Therapy for Ameloblastic Carcinoma of the Maxilla: Report of a Rare Case. J Oral Maxillofac Surg 2019;77:227.e1-5.

16. Kikuta S, Furukawa Y, Hino K, et al. Huge ameloblastic carcinoma of the mandible with metastases treated in several different ways. Br J Oral Maxillofac Surg 2019;57:182-4.

17. Aoki T, Akiba T, Kondo Y, et al. The use of radiation therapy in the definitive management of ameloblastic carcinoma: a case report. Oral Surg Oral Med Oral Pathol Oral Radiol 2019;127:e56-60.

18. Smitha T, Priya NS, Hema KN, et al. Ameloblastic carcinoma: A rare case with diagnostic dilemma. J Oral Maxillofac Pathol 2019;23:69-73. 


\section{Page 8 of 8}

19. Kosanwat T, Poomsawat S, Juengsomjit R. Ameloblastic carcinoma ex ameloblastoma of the maxilla. J Oral Maxillofac Pathol 2019;23:58-62.

20. Cho BH, Jung YH, Hwang JJ. Ameloblastic carcinoma of the mandible: A case report. Imaging Sci Dent 2020;50:359-63.

21. Shrikaar M, Suwasini S, Chatterjee K, et al. Maxillary ameloblastic carcinoma: A diagnostic conundrum. J Oral Maxillofac Pathol 2021;25:159-62.

22. Salehani A, Mooney J, Lepard J, et al. Rare Ameloblastic Carcinoma Metastasis to the Cervical Spine: A Case Report. Neurosurgery 2021;88:E537-42.

23. Effiom OA, Ogundana OM, Akinshipo AO, et al. Ameloblastoma: current etiopathological concepts and management. Oral Dis 2018;24:307-16.

24. Dhir K, Sciubba J, Tufano RP. Ameloblastic carcinoma of the maxilla. Oral Oncol 2003;39:736-41.

25. Speight PM, Takata T. New tumour entities in the 4th edition of the World Health Organization Classification of Head and Neck tumours: odontogenic and maxillofacial bone tumours. Virchows Arch 2018;472:331-9.

26. Elzay RP. Primary intraosseous carcinoma of the jaws. Review and update of odontogenic carcinomas. Oral Surg Oral Med Oral Pathol 1982;54:299-303.

Cite this article as: $\mathrm{Xu}$ Z, Shang J, Yang N, Long L, Zhang P. Reconstruction of soft tissue defect after maxillectomy of ameloblastic carcinoma with submental island flap: a case report and literature review. Ann Transl Med 2021;9(23):1746. doi: 10.21037/atm-21-5196
$\mathrm{Xu}$ et al. Ameloblastic carcinoma: a rare case involving in maxilla

27. Slootweg PJ, Müller H. Malignant ameloblastoma or ameloblastic carcinoma. Oral Surg Oral Med Oral Pathol 1984;57:168-76.

28. Kruse AL, Zwahlen RA, Grätz KW. New classification of maxillary ameloblastic carcinoma based on an evidencebased literature review over the last 60 years. Head Neck Oncol 2009;1:31.

29. Niu Z, Li Y, Chen W, et al. Study on clinical and biological characteristics of ameloblastic carcinoma. Orphanet J Rare Dis 2020;15:316.

30. Lenox ND, Kim DD. Maxillary reconstruction. Oral Maxillofac Surg Clin North Am 2013;25:215-22.

31. Martin D, Baudet J, Mondie JM, et al. The submental island skin flap. A surgical protocol. Prospects of use. Ann Chir Plast Esthet 1990;35:480-4.

32. Faisal M, Adeel M, Riaz S, et al. The Submental Island Flap in Head and Neck Cancer. Ann Maxillofac Surg 2018;8:287-91.

33. Sittitrai P, Srivanitchapoom C, Reunmakkaew D, et al. Submental island flap reconstruction in oral cavity cancer patients with level I lymph node metastasis. Br J Oral Maxillofac Surg 2017;55:251-5.

(English Language Editor: R. Scott) 